\title{
MUCAJÁ DO CURIAÚ: UM RELATO SOBRE SEU SABOR NA FORMAÇÃO DE UMA ECONOMIA IDENTITÁRIA
}

\section{MUCAJÁ OF CURIAÚ: A REPORT ON YOUR FLAVOR IN THE FORMATION OF AN IDENTITY ECONOMY}

Fabrícia Luane da Silva Santos ${ }^{[1]}$; Ricardo Soares Nogueira ${ }^{[1, *]}$; Soraia Campos Carvalho ${ }^{[2]}$ e Wanne de Araújo Rodrigues $^{[1]}$

\author{
[1] Instituto Federal do Amapá, Campus Macapá. Rod. BR 210 km 03, s/n. Bairro Brasil Novo, CEP: 68.909-398. Macapá, AP - Brasil. \\ ${ }^{[2]}$ Membro do Grupo de Pesquisa em Religiosidades Aplicadas às Humanidades. email: laiaccampos@gmail.com \\ *Autor para correspondência: ricardo.nogueira@ifap.edu.br \\ INFORMAÇÃO \\ RESUMO
}

Recebido em: $28 / 08 / 2015$

Aceito em: $24 / 03 / 2016$

Publicado em: 06/04/2016

Document Object Identifier

10.18067/jbfs.v3i1.54

Editor: V. H. G. Sales

jbfs@ifap.edu.br

ID JBFS2015054

Prot. $0542016 E D 01$

Copyright: (C) 2016

JBFS all rights (BY NC SA)
O presente trabalho é resultado das atividades do Grupo de Pesquisa em Religiosidades Aplicadas às Humanidades, o qual os membros autores são participantes. Seu conteúdo versa sobre o mingau preparado com a fruta amazônica do mucajazeiro, utilizada como base alimentar da comunidade do Curiaú, marcada pela pobreza econômica de seus moradores que buscavam no fruto sua base alimentar. Como também acentua possibilidades de preparo de produtos derivados e sua aceitação no comércio local. Curiosamente ao mingau adicionam-se partes do crustáceo sarará como inibidor da consistência pegajosa do fruto. Por fim, este trabalho apresenta como o mingau está relacionado aos festejos de São Joaquim, padroeiro da referida comunidade, além de apontar possibilidades para o uso do fruto em outras tecnologias de alimentos.

Palavras-chave: Curiaú; Religiosidade; Mingau; Tecnologia de alimentos

ABSTRACT -. This work is the result of the activities of the Research Group in Applied Religiosities the Humanities, which the authors members are participants. Its content deals with the porridge prepared with Amazonian fruit of mucaja, used as a food base of Curiaú community, marked by economic poverty of its residents seeking fruit in their food base. But also accentuates preparation possibilities of derivatives and their acceptance in the local market. Interestingly the porridge add up parts of crustacean heal as an inhibitor of sticky consistency of the fruit. Finally, this paper presents as the porridge is related to the celebrations of St. Joachim of that community patron, while pointing out possibilities for the use of the fruit in other food technologies.

Keywords: Curiaú, Religiosity, Porridge, Food Technology

Financiamento: Os autores reportam que não houve suporte e auxílio financeiro.

Conflito de interesse: Os autores declaram que não há conflito de interesse.

Direito de Imagem: $O$ autor principal reporta que as imagens das pessoas foram autorizadas para publicação por meio da assinatura do termo de consentimento livre e esclarecido.

Como referir esse documento (ABNT):

SANTOS, F.L.S.; NOGUEIRA, R.S.; CARVALHO, S.C.; RODRIGUES, W.A. mucajá do curiaú: um relato sobre seu sabor na formação de uma economia identitária. Journal of Bioenergy and Food Science, Macapá, v.3, n.1, p.58-62, jan./mar., 2016. DOI:10.18067/jbfs.v3i1.54

\section{INTRODUÇÃO}

Este estudo tem como objetivo resgatar os conhecimentos tradicionais relativos ao fruto do mucajazeiro e o seu uso no preparo do mingau de mucajá e outros derivados, sendo o primeiro servido nos festejos de São Joaquim, padroeiro da comunidade quilombola do Curiaú. Aos pesquisadores o que provocou a curiosidade epistemológica foi à percepção das contribuições do conhecimento empírico que identificou no sarará um ingrediente capaz de neutralizar a viscosidade 
do fruto, sendo fácil de ser encontrado na região. 0 sarará ou aratu (Armases benedicti) é um crustáceo rico em fósforo e cálcio que mede $1,8 \mathrm{~cm}$ de largura e é encontrado em toda a orla de Macapá, no Rio Amazonas. A partir desta realidade cogitou-se a possibilidade da fruta ser utilizada como fonte alimentar em iogurtes, sorbets e geleias.

Do mucajá do Curiaú sabe-se que em um período de escassez de recursos financeiros e alimentos, o descontentamento entre os provedores do lar era enorme, tanto que ao contemplar o rumo da cidade de Macapá, referiamse a ela como "o lugar que Deus nos quer bem", e que tinham no mingau de mucajá sua fonte para combater a subnutrição e agregar culturalmente as famílias da localidade.

Para o preparo do mingau do mucajá, por exemplo, caminhavam alguns metros dentro da ressaca criada pelo Rio Curiaú até se chegar aos mangues formados no delta com o Rio Amazonas para capturar o sarará, pois, o uso de seus membros no mingau é resultado do encontro de informações repletas de manifestações religiosas, uma vez que as pessoas caminham ao som de ladainhas e jaculatórias.

Para reviver esta experiência fez-se necessário percorrer os caminhos do mangue para encontrar o crustáceo. Durante os anos de 2013 e 2014 o Rio Amazonas foi o cenário para a captura do sarará ao som de cantos devocionais, como demonstrado na figura 1.

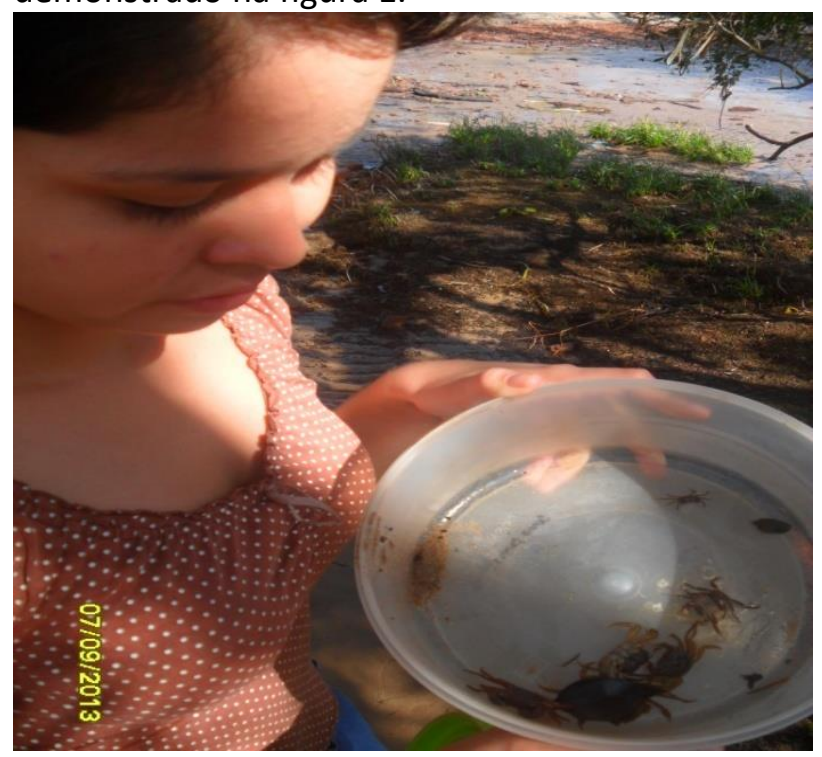

Figura 1. Estudante membro do $\mathrm{GPRHUM}^{1}$ coletando o sarará no bairro Perpétuo Socorro, orla de Macapá-AP.

Figure 1. Student member of GPRHUM, collecting the "Sarara" in the "Perpetuo Socorro" neighborhood, orla of Macapa-AP, Brazil.
É de fácil localização no youtube, o internacionalmente premiado mingau de mucajá do seu Vavá, cidadão de forte personalidade do município paraense de Ourém, que há anos já vem comercializando o referido produto nas praças da cidade ao entardecer. Porém, o seu Vavá não apresenta traços de religiosidade no preparo, como é no caso do Curiaú, assim como não avalia o potencial da fruta em outros produtos e sua aceitação comercial em uma escala quiçá maior.

Quanto ao mucajá, para conhecê-lo melhor, o mesmo apresenta a seguinte taxonomia: Reino Plantae, Divisão Magnoliophyta, Classe Liliopsidae arecidae, Ordem Arecales, Família Arecaceae, Gênero Acrocomia aculeata e Espécie Spermatophyta.

\section{MATERIAL E MÉTODOS}

Os frutos de mucajá foram colhidos na zona rural de Macapá, compreendendo a vasta área de preservação ambiental do quilombo do Curiaú. $\mathrm{Na}$ residência dos membros do Grupo de Pesquisa. Os frutos foram lavados, sanitizados com água clorada a $50 \mathrm{ppm}$ por aproximadamente 10 minutos, enxaguados em água corrente para a retirada do excesso de sanitizante e secos.

Os produtos de mucajá como o iogurte, a geleia e o sorbet foram avaliadas sensorialmente por 100,30 e 30 provadores respectivamente selecionados aleatoriamente, não treinados, com idades de 14 a 50 anos, constituídos por servidores e discentes da rede pública do Amapá e do Instituto Federal do Amapá (Ifap), campus Macapá.

Os testes utilizados na pesquisa foram: teste de aceitação e intenção de compra.

No teste de aceitação das amostras dos produtos derivados do mucajá, foi utilizado um formulário, com escala hedônica de 8 pontos estruturados, variando de "não gostei, nem desgostei" a "gostei muitíssimo", de acordo com a metodologia proposta por Dutcosky. ${ }^{2}$

Para o teste de intenção de consumo, foi utilizado um formulário com escala verbal de 3 perguntas sendo elas: "compraria", "não compraria" e "talvez compraria".

Para verificar a aceitação dos produtos, foi realizado o cálculo do índice de 
Aceitabilidade (IA), isto é, o número de respostas dadas dividido pelo número de provadores multiplicado por cem, dando a porcentagem de cada um.

Com base nos estudos de Dutcosky ${ }^{2}$ a experimentação realizada, considerou epistemologicamente que a atividade moderna desenvolvida na cidade de Macapá pelo trabalho organizado teve pouco impacto nas famílias do Curiaú. Pois, grande parte dos que desenvolvem suas atividades na capital, procuram de alguma forma conciliar seu tempo para poderem trabalhar na agricultura e na pecuária bubalina e frequentam o Curiaú apenas nos finais de semana para o lazer e o descanso ou então para bailes e festas noturnas com ênfase na religiosidade de cada família que é devota de um santo do catolicismo popular e sincrético. Essa devoção se observa nas várias imagens católicas romanas que tradicionalmente as festejam com fé e veneração. Inclusive, e essa vocação festeira da comunidade, foi o meio encontrado para preservar, através de comemorações religiosas, sua herança africana, o latim e os laços de parentesco.

Marcadas pelo sincretismo religioso, comemorações conjugam elementos profanos, tais como o Batuque e o Marabaixo, com rituais religiosos, como as ladainhas em latim, a Procissão e a Folia ${ }^{3}$. Uma mostra desse sincretismo pode ser vista na festa de São Joaquim, um dos padroeiros do Curiaú. Nesta festa, que ocorre ao longo dos dez dias entre o dia 9 e 19 de agosto, as comunidades que formam a Área de Proteção do Curiaú reúnemse para cantar as Ladainhas, caindo, pouco depois, no ritmo quente dos tambores. $E$ até pouco tempo atrás, a comunidade conservava na igrejinha dedicada ao santo, um Altar para celebração da Santa Missa em Versus Dei, caído em desuso pela aproximação com a cidade e a segunda modernidade.

\section{PESQUISA DE CAMPO}

Nas festividades, onde o mingau era servido, não havia interesse lucrativo, mas este era servido como uma forma simbólica e cultural de fraternidade e espiritualidade cristã. Segundo Dona Minerva: "O homem deve agir racionalmente com a natureza para aproveitar todos os recursos possíveis extraídos sem agredi-la".

O conhecimento tradicional é um sistema integrado por crenças e práticas, características de grupos culturais diferentes e povos tradicionais. $\mathrm{E}$ estes, geralmente afirmam que a "natureza" para eles não é somente um inventário de recursos naturais, mas representa também as forças espirituais e cósmicas que fazem da vida o que ela $e^{4}$.

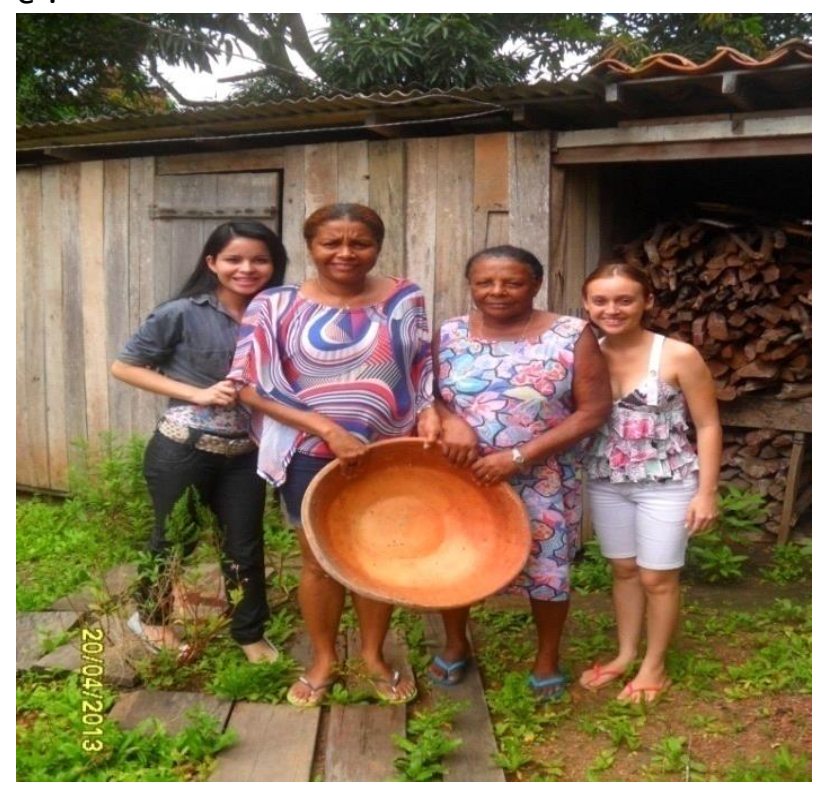

Figura 2. Da esquerda para direita: Wanne Araújo, Marilda Leite, Minerva Leite e Lílian Carvalho

Figure 2. From left to right: Wanne Araújo, Marilda Leite, Minerva Leite and Lílian Carvalho

Deste modo, tornou-se essencial a utilização para coleta de dados o método etnográfico. Entre as técnicas deste método citam-se: observação participante, entrevistas formais e informais sendo gravadas ou anotadas, sondagens e história de vida. Como na fotografia acima, observa-se como as mulheres do Curiaú socializam sua cultura, a bacia apresentada é utilizada no preparo do mingau do mucajá onde rezas envolvendo o magismo e o animismo também estão presentes, misturando-se ao catolicismo romano. Isso comprova que o mais proveitoso é combinar as diversas formas de coleta de dados, de acordo com os interesses e a situação de campo.

\section{RESULTADOS E DISCUSSÃO}

Foram realizadas pequenas entrevistas com a família de dona Minerva Leite Pereira ${ }^{5}$, contando com sua experiência de vida. Conta-nos ela que "em tempos de festança a vizinhança toda se reúne e faz o mingau de Mucajá sem fins lucrativos, pois é algo que é servido desde muito tempo e vem sendo repassado de geração em geração". 
É mister afirmar que as visitas de campo nos deixaram um legado ímpar quanto ao conhecimento de nossa cultura regional, assim como nos possibilitou, no campo teórico e pedagógico, a compreensão da temática da interdisciplinaridade e da reflexão crítica, muitas vezes não compreendidas em nossas práticas escolares.

A pesquisa sobre o mingau do mucajá abriu novos horizontes para a formação dos Técnicos em Alimentos do IFAP, possibilitando mensurar o conteúdo de excelência ministrado em nossos laboratórios com a pesquisa e inovação de novas fontes alimentares que necessitam da ciência e da tecnologia para serem exploradas em prol da sociedade macapaense.

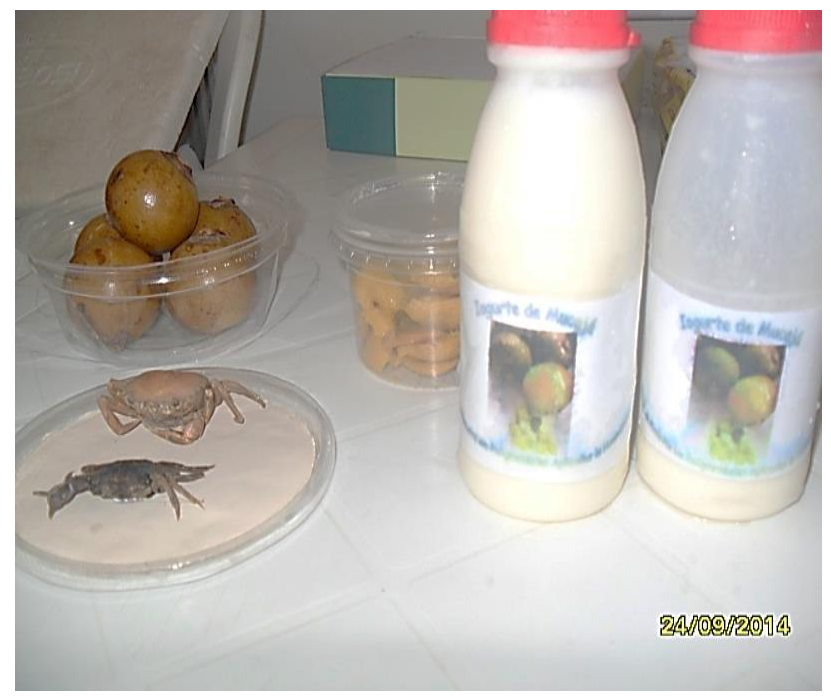

Figura 3. Fruta in natura, polpa, sarará e iogurte como produto final.

Figure 3. Fruit in natura, pulp, "Sarará" and yogurt as a final product

Uma destas possibilidades é a fabricação de iogurtes, geleias, etc. feitos com o mucajá. Tal experiência fora apresentada durante a I Mostra Técnica e Tecnológica do IFAP de 23 a 26 de setembro de 2014 na sede do SEBRAE Macapá, onde o iogurte de mucajá teve boa aceitabilidade por parte de quem visitou a feira, conforme demonstrase nos resultados estatísticos do Teste de Aceitabilidade que aplicamos.
Teste de Aceitabilidade do logurte de Mucajá

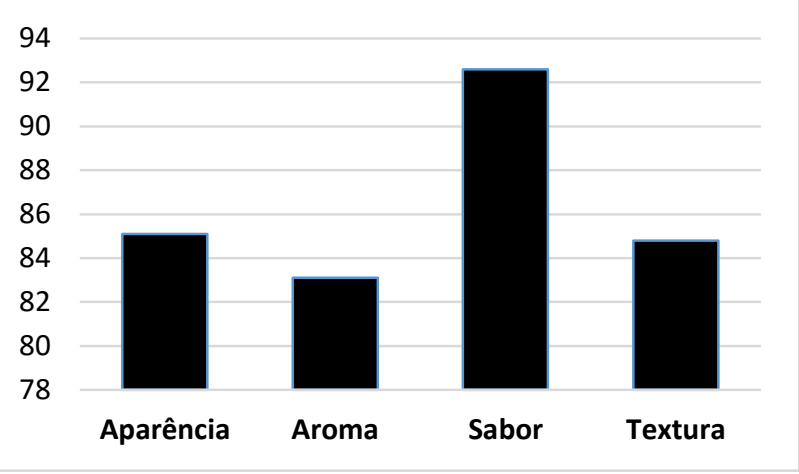

Teste de intenção de compra para o iogurte de Mucajá

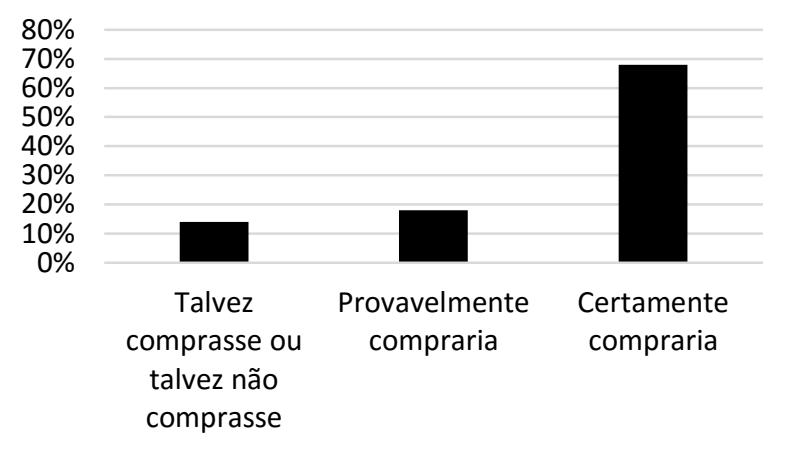

Teste de aceitabilidade da geleia de Mucajá

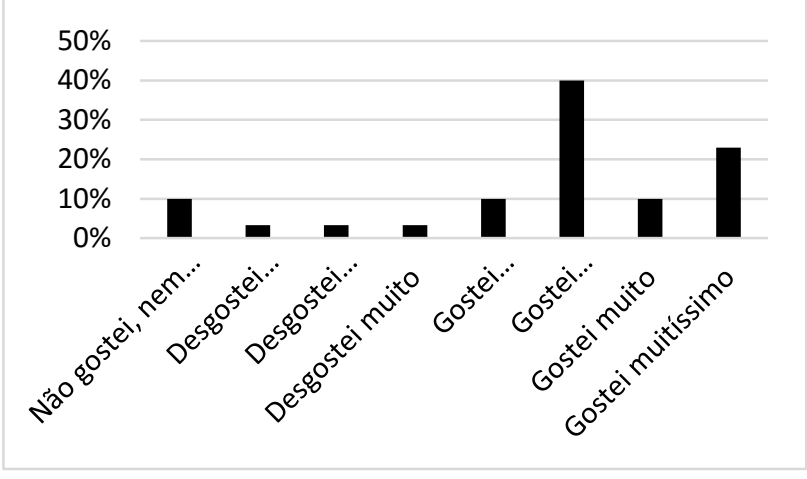

Intenção de compra da Geleia de Mucajá

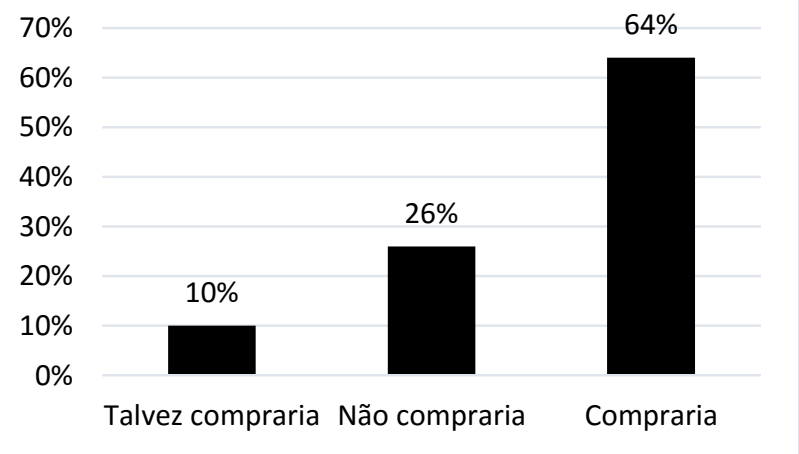


Estes gráficos supra demostrados resultam da avaliação de aceitabilidade do iogurte considerando desde a aparência, o aroma, o sabor e a textura culminando na aprovação por parte dos visitantes da Feira Científica em relação ao produto.

Outra oportunidade para verificação da aceitabilidade dos derivados do mucajá se deu na Semana Nacional de Ciência e Tecnologia no dia 20 de outubro de 2015, em uma análise sensorial dos produtos geleia e sorbet com sessenta estudantes dos cursos do ensino médio integrado do Campus Macapá, sendo trinta avaliadores para cada produto. Obtendo-se os seguintes resultados.
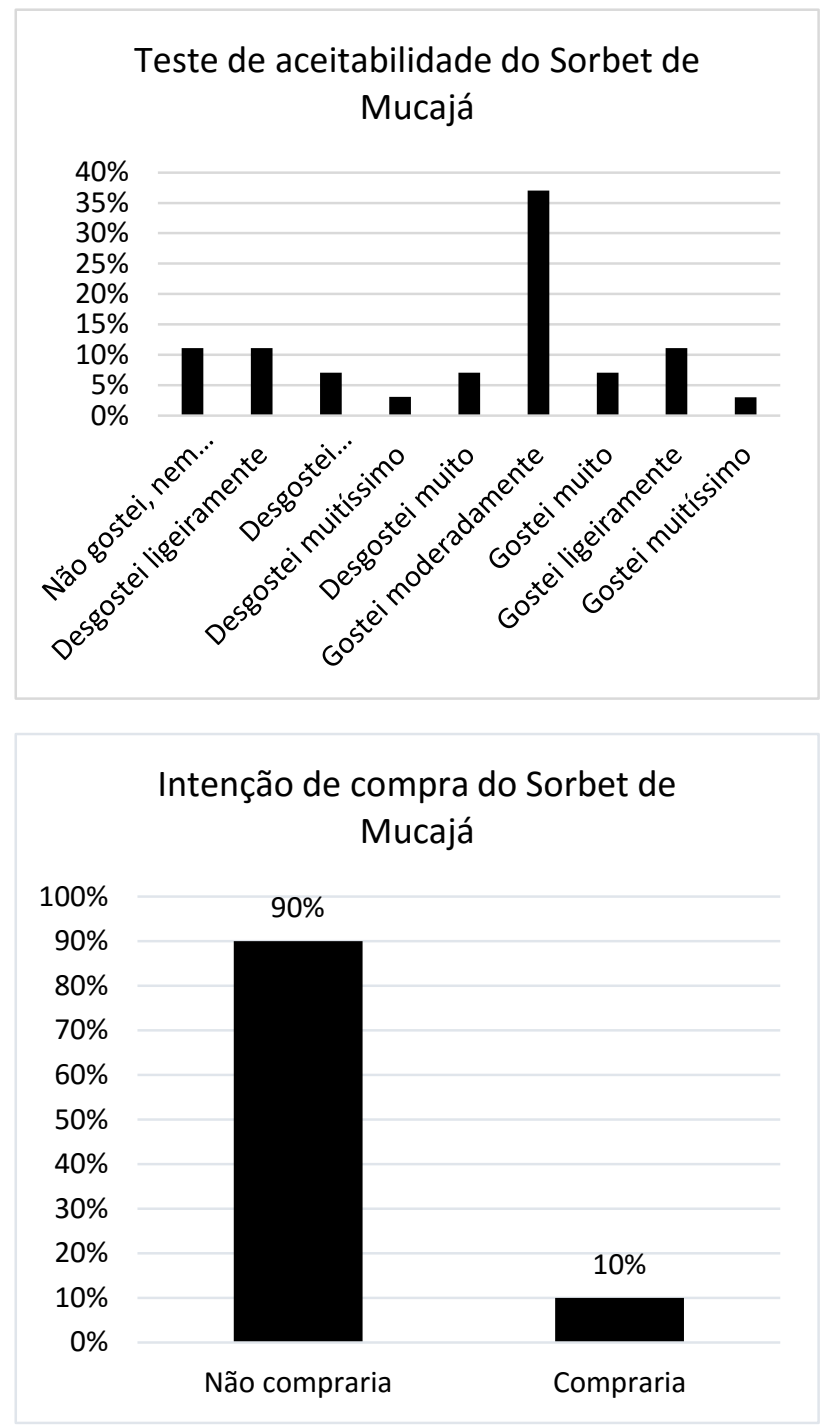

Assim, verificou-se que os avaliadores tendo familiaridade com o fruto, não vislumbravam as possibilidades de produtos alimentícios derivados do mesmo. Foi inusitado pelo fato de ser uma fruta nativa pouco consumida pelas famílias macapaenses que residem na zona urbana. Pelo fato da geleia e do iogurte serem mais conhecidos do público, o sorbet foi uma grande novidade, provocando um resultado diferenciado dos demais.

Também um dos produtos derivados do mucajá, no caso a geleia, foi oportunizada para apresentação e degustação durante o X Congresso Norte Nordeste de Pesquisa e Inovação (CONNEPI), que ocorreu na cidade de Rio Branco-AC, no período de 31 de novembro a 03 de dezembro de 2015. Este fez parte da Mostra Tecnológica do Universo IF. Na ocasião foi apresentada para degustação a fruta e a geleia, seguido de debates e discussões a respeito do mucajá e propostas futuras. Como por exemplo, em conversa com Sr. Belchior de Oliveira Rocha, presidente do CONIF (Conselho Nacional das Instituições da Rede Federal de Educação Profissional, Cientifica e Tecnológica), houve a orientação para uma proposta da possível análise do valor nutricional do mucajá.

\section{CONSIDERAÇÕES FINAIS}

Como percebido, são de fácil aceitação alguns produtos derivados do mucajá, assim como tem sido educativo aos estudantes a (re)descoberta das suas raízes culturais, propondo uma identidade comercial típica de nossa região. Em nossa avaliação da atividade foi cogitado a possibilidade dos produtos derivados do mucajá aprovados no teste de aceitabilidade de serem comercializados pelas famílias em suas próprias casas aos finais de semana e feriados, uma vez que a APA do Curiaú e seu balneário são pontos turísticos de Macapá.

Por ser costume aos finais de semana as famílias quilombolas se sentarem na frente de suas residências para comercializar bolos, tapiocas, sucos e outras comidas típicas, mercadologicamente, os produtos derivados do mucajá podem criar uma identidade local, a preservação ambiental da palmeira, além do consumo saudável e sustentável e da valorização da cultura alimentar tradicional que estão ganhando espaço nas pesquisas científicas, despertando interesse do Grupo de Pesquisa em Religiosidades Aplicadas às Humanidades.

Os sabores proporcionados pelo mucajá e a possibilidade de uma economia sustentável e com qualidade de vida serviram de motivação inicial ao presente trabalho, assim como todo escopo em deixar com que a comunidade construísse sua própria autonomia sempre foram uma constante entre os membros do GPRHUM. 
Por fim, os trabalhos iniciados em meados de 2013 acerca desta possibilidade de atividade teórico-prática envolvendo aspectos pedagógicos do ensino e da pesquisa na Rede Federal de Educação Tecnológica, a qual o IFAP faz parte tem sido sumamente importante na medida em que possibilita ao corpo docente e ao corpo discente uma aproximação com a religiosidade nas comunidades tradicionais do Estado do Amapá açambarcando visões e interpretações interdisciplinares trazendo comunidade para a ciência e levando ciência para comunidade, desenvolvendo habilidades e competências no alunado envolvido e permitindo um legado inquestionável às referidas comunidades do Curiaú tanto no conhecimento como na potencialidade de geração de renda e educação ambiental.

\section{CONTRIBUIÇÃO DOS AUTORES}

1 - Planejamento, elaboração e revisão final do artigo

Ricardo Soares Nogueira

Soraia Campos Carvalho

2 - Pesquisa de campo

Wanne de Araújo Rodrigues

Fabrícia Luane da Silva Santos

\section{REFERÊNCIAS}

1. GPRHUM. Grupo de Pesquisa em Religiosidades Aplicadas às Humanidades. Disponível em:

<www.gprhum.forumeiros.com>. Acesso em 19 de maio de 2015 às $16 h 36$.

2. DUTCOSKY, S.D. Análise Sensorial de Alimentos. 4 ed. Curitiba: Champagnat, 2013, p. 334.

3. CANTO, 1980 apud SILVA, Raullyan Borja Lima e. A etnobotânica de plantas medicinais da comunidade quilombola de Curiaú, Macapá-AP, Brasil. 2002. 13p. Dissertação (Mestrado em Agronomia) - Universidade Federal Rural da Amazônia, Belém 2002.

4. POSEY, D. A. Etnobiologia e etnodesenvolvimento: importância da experiência dos povos tradicionais. In: SEMINÁRIO INTERNACIONAL SOBRE MEIO AMBIENTE, POBREZA E DESENVOLVIMENTO DA AMAZÔNIA, 1992, Belém. Anais. Belém: Governo do Estado do Pará. P. 112117.

5. PEREIRA, M.L. Entrevista concedida no dia 20/04/2013 aos membros do GPRHUM. 